\title{
What It Takes To Succeed In The Philippine Nursing Licensure Exam? A Retrospective Qualitative Inquiry on the Journey of Thomasian Board Topnotchers
}

\author{
Marica G. Estrada, PhD, $\mathbf{R N}^{\mathbf{1}^{*}}$, April Joy M. Gascon, MAN, RN ${ }^{\mathbf{1}}$, La. Arnie M. Lazalita, MAN, $\mathrm{RN}^{\mathbf{1}}$ \\ ${ }^{1}$ College of Nursing, University of Santo Tomas, Espana, Manila 1015, Philippines
}

\begin{abstract}
:
Background: Over a decade, only less than $60 \%$ of the total number of examinees passed the Nursing Licensure Examination. A steady decline in the Philippine Nurses Licensure Exam (PNLE) national passing rate was noted from years 2004 to 2014 with a range of 30.94 to 57.29 percent for the ten year board ratings (PRC, 2014).

Methods: This retrospective qualitative inquiry made an attempt to explore the experiences of 13 thomasian PNLE topnotchers who successfully outshined the Philippine Nurses Licensure Exam for the past three years (2012-2014).

Findings: Four emerging themes and eight subthemes captured what the thomasian topnotchers have done to attain their ranks in the Philippine Nurses Licensure Exam. Four success targets were identified and achieved in hierarchy that clearly guided them to maintain academic rigor and reach academic victory. These are the following; Visualize Success, Begin Early, Do more than what you can and Transform your own learning.
\end{abstract}

Keywords: Philippine Nursing Licensure Examination, Thomasian board topnotchers,success progress, success targets

\section{INTRODUCTION}

Over a decade, only less than $60 \%$ of the total number of examinees passed the Philippine Nursing Licensure Examination (PNLE). Recent data gathered from Professional Regulation Commission (PRC) revealed a steady decline in the PNLE national passing rate from years 2004 to 2014. A range of 30.94 to 57.29 percent was noted for the ten year board ratings, lowest passing rate of 30.94 percent was noted in December 2013 while the highest passing rate of 57.29 percent was gained last November 2014. Ordonez and Ordonez (2009) claimed that the decrease in the passing rate of Filipino graduates in the various licensure examinations is a symptom of depreciating educational quality offered by higher education institutions in the Philippines.

Notably, the national passing rate has not changed nor improved despite the fact that the number of board takers for the nursing licensure exam decreased for the past ten years. About 94, 462 examinees registered the highest number in November 2009 to 12, 100 examinees as the smallest in December 2004. The strict regulation of nursing schools in the country and the accreditation requirements set by the Commission on Higher Education (CHED) and Board of Nursing (BON) were the primary reasons for the sudden decline. This initiative was supported by the study of Dator (2010) who raised the significance of school's accreditation to its performance in NLE. Schools who were accredited performed better in the PNLE compared to non-accredited schools.

Interestingly, the University of Santo Tomas (UST) College of Nursing has consistently outshined the Philippine Nurses Licensure Exam for more than decades. The UST College of nursing is consistently included in the Top Ten Performing schools in the country and has maintained 98.28 to 99.79 percent passing rate for the past eight years and has produced 149 PNLE topnotchers since year 2007. A range of 8 to 29 Thomasian nurse graduates have been recognized as PNLE topnotchers for eight consecutive years and three female thomasian graduates dominated and ranked first in June 2008, June 2012 and May 2014 nursing licensure exam.

A lot of factors could play significant roles in determining whether a student would pass the examinations or not. These factors should be identified and studied in order for us to improve the system of preparation the nursing students undergo before taking the exams. Identification of factors associated with student success in the Philippine

${ }^{1 *}$ Corresponding Author: estradamarica@yahoo.com 
Nursing Licensure Examination (PNLE) is critically important for colleges of nursing with diverse student populations. There is still a pressing need for professional regulatory boards, administrators and educational institutions to conduct studies that would identify the factors that affect the success and failure rates of applicants taking the PNLE.

This retrospective qualitative inquiry made an attempt to explore the experiences of the thirteen thomasian board topnotchers for the past three years (2012-2014). The study aims to reveal their behavioral constructs and highlight how these behaviors helped them achieve success in the Philippine Nursing Licensure Exam. Further, the study aims to identify themes to understand their experiences and reveal the attributes of a Thomasian Board Topnotcher.

Moreover, the findings of the study, will contribute to the few literatures available in the country that highlighted factors predicting success in PNLE. Graduate nurses from other colleges and universities may utilize the findings as benchmarks to create strategies to assist nursing graduates to achieve life-long professional success and stability.

To better understand the phenomenon, the following questions will be raised:

Research Question 1: What describes your experience as you prepare for the PNLE?

Research Question 2: What have you done to successfully achieve as a PNLE Topnotcher?

Research Question 3: What do you think has helped you the most to achieve your success?

Research Question 4: What impact does it create in your profession and in your life at present?

\section{REVIEW OF LITERATURE}

Passing the Philippine Nursing Licensure Exam (PNLE) is the key to practice the nursing profession. The Philippine Nurse Licensure Exam (NLE) is a 500 item multiple-choice examination prepared by the Board of Nursing (BON) to test first level nursing competencies. The exam consists of five parts that covers the following subjects namely Basic Foundation of Nursing and Professional Nursing Practice, Community Health Nursing and Care of Normal and High Risk Mother and Child, and Care of the Clients with Physiologic and Psychosocial Alterations (Parts A, B, and C).Graduates of nursing schools in the country must pass a competency based examination before they can legally practice nursing as a profession. To be able to pass the exam, the candidate must obtain a general average of at least 75 percent with a rating of not below 60 percent in any of the five test subjects. The results of the nurse licensure exam are considered as main determining factor for the quality of nursing education provided in the country.

In a study conducted by Rosales, Arugay, Divinagracia \& Palaganas (2014), the performance in NLE reflects the state of Nursing Education in the country. Nursing programs must strive to offer an educational experience that will train the graduates towards competence. Passing the NLE provides evidence that a graduate has learned enough basic competencies and functions to practice the nursing profession and be given the title of a registered nurse. The PNLE (Philippine Nursing Licensure Examination) is the board examination held by the Professional Regulation Commission of the Philippines to grant licenses to Filipino applicants who desires to practice the nursing profession in the country.

A study made by Erlinda Castro Palaganas, Carmelita Dela Cruz Divinagracia and Amelia B. Rosales (2012), discussed the performance of the graduates of Philippine Colleges of Nursing in the NLE for 8 consecutive NLEs in the Philippines and its implications to the policy. This study used a descriptive correlational design with the purpose of describing the examinees' performance and identifying the factors that may have affected these performances. Divinagracia, Palaganas, and Rosales (2012) stated that accreditation status has a strong predictive ability and that examinees who graduated from schools with level 3 accreditation status obtained high passing percentage and average rating in all the NLEs. Testing centers were also identified as one of the variables which influence the performance of the examinee (Divinagracia, Palaganas, and Rosales, 2012). The study concluded that variations in NLE results related to the examinee, the school where the examinee obtained one's BSN degree and other variables, such as the test subject and the testing center where the NLE was administered were observed (Divinagracia, Palaganas, and Rosales, 2012).

Most of the available literatures in the country focused on the evaluation of several variables such the examinee background (first timer, repeater, and school graduated), institutional (accreditation status, school ownership, geographic location and number of examinees), program (test subject, testing centers) and other variables such as performance in the five test subjects of NLE for policy development and enhancement. 
Prior research has established that both personality traits and learning styles are associated with academic achievement (Jeffreys, 2015). In the current research, gaps in the literature examined relationships between personality learning styles, and academic achievement and by examining the extent to which relationships between personality and academic achievement (Jeffreys, 2015; Komarraju, Karau \& Schmeck, 2009; McLaughlin, et al., 2008). Bristol (2012) focused on other academic variables such as learning strategies that predict student success. In the country, little is known about the success profile of topnotchers as to their behavior and practices as they prepare for the exam.

\section{METHODS}

Employing the descriptive phenomenological inquiry, the purpose of this study is to explore behavioral indicators to success of Thomasian Board Topnotchers in the Philippine Nursing Licensure Exam (PNLE) for the past three (3) years and significantly contribute to current literature on Nursing Education and Research. This method of investigation is a recognized research approach applicable in describing and transforming into language the phenomena of human experiences. The qualitative research design is chosen as an appropriate method to capture the experiences of Thomasian Board Topnotchers as they successfully top the Philippine Nursing Licensure Exam (PNLE).

\subsection{Sample and Study Site}

This study aims to explore the experiences of Thomasian Board Topnotchers as they prepare and successfully top the Philippine Nurses Licensure Exam for the past three years, 2012-2014. For this reason, participants of this study involved graduate Thomasian nurses who ranked first to tenth in the past three years of the nurse licensure exams. The study made use of purposive, convenient (based on their ability and willingness to cooperate), non-random sampling. This was done to get the best result that allowed the researcher obtain and interpret the most essential and pertinent information needed in answering and analyzing research inquiries. The researchers established the following criteria for the participants included in the study. First, a Thomasian graduate nurse, male or female who belong to the Top 1 to 10 Rank in the Philippine Nurses Licensure Exam for the last three years (2012, 2013 and 2014) and lastly, willing to participate in the study.

\subsection{Instruments}

A researcher made, semi-structured survey questionnaire was used to access and capture the lived experiences of the research participants. The first part of the survey questionnaire contains their demographic profile as to name, gender, age, year graduated, PNLE rank, work history and highest educational attainment. The second part contains six open-ended questions that allowed the participants to describe their experiences as they prepare for the board exam and share what they have done to successfully top the nursing licensure exam.

\subsection{Data gathering procedure}

The researcher identified Thomasian PNLE topnotchers for the past three years, retrieved their email addresses and sent an invitation to participate in the study via electronic mail. A primer was attached to the electronic mail that contains the purpose and nature of the study, reason for participation, and the benefits and risks written in full detail. The participants were informed of their rights as a participant and shall be asked to sign the consent form and resend the file to the email address of the researcher as they voluntarily decide to be involved in the study. After the identified topnotchers sent their replies via e-mail, a survey questionnaire was sent that uncovers their behavioral constructs as topnotchers.

\subsection{Data Analysis}

The narrative accounts were dealt by the researcher individually. A repertory grid was developed to aid the phenomenological reduction through cool and warm analyses. Also, the researcher adopted Colaizzi's 9 procedural steps (Colaizzi, 1978). First, the researcher described the phenomenon of interest. Second, collect the participants' descriptions of the phenomenon and then read all of it. After this, the researcher tried to spell out the meaning of each significant statement then organize the aggregate formalized meanings into clusters of themes. The next step was integrating the findings into an exhaustive description of the participants' lived experiences. The researcher returned to the participants for the validation of the description by sending the findings individually. If new data are revealed during the validation of the description, the researcher incorporated them into the exhaustive description. (Colaizzi, 1978 as cited by Speziale and Carpenter, 2011). Lastly, describing involved classifying all critical elements or essences that are common to the experiences of the participants and described these experiences in full detail (Streubert \& Carpenter, 2011). 


\subsection{Ethical Considerations}

The researchers submitted the proposal of the study to the Ethics Review Board for external reviews about the proposed procedure to assure and protect the participant's rights and to prevent the risk of biased evaluation. Further, the researchers conducted the study based on the following ethical principles. Principle of selfdetermination was observed by having the participants voluntarily decide whether or not to participate in the study. Also, the participants were given the right to communicate questions, to refuse to give information, and or to withdraw from the study anytime if they wish to do so. Principle of self-determination gave the participants the freedom from coercion of any type. In line with this, the principle of non-maleficence was followed wherein participants were not engaged in activities that can cause harm, risk or discomfort, and their participation to the research should be essential enough to achieve the aims of the researchers.

\subsection{Establishing Rigor of the study}

Consistent use of the method and bracketing by putting aside prior pre-conceived beliefs about student and graduate nurses academic behavior and success helps to ensure pure description of the data was observed to maintain Credibility. Member checking was done described by going back to the participants to confirm if they recognize the findings as true to their experiences. This will determine the accuracy of the qualitative findings (Creswell, 2003).The confirmability of the findings will be documented using audit trail. This process records the activities done over time and allows the reader to clearly follow the line of thinking that the researcher used during data analysis. The results of the study will be used as a significant framework in understanding the Thomasian Board Topnotchers experiences as they successfully top the Philippine Nurses Licensure Exam.

\section{FINDINGS}

Based from the collected narrative accounts of thirteen (13) Thomasian Board Topnotchers, four emerging themes were identified that undoubtedly denotes their experience of success from the time they were accepted as student nurses until they have outshined the Philippine Nurses Licensure Exam. Four (4) emerging themes and eight (8) subthemes were revealed from the respondents' statements of success. The four emerging themes are the following: First, Dreamed Beyond Our Seeing, Second, Embodied the Culture of Excellence, Third, Touched with the Flame of Kindness, and Fourth, Imbued with Unending Grace. Most of the names of the emerging themes were lifted from some of the words in the University of Santo Tomas Hymn that marks the true Thomasian Identity. The eight subthemes that completely describe the four emerging themes are as follows: Envision Success, Begin Early, Innovate Learning, Engage Vigorously, Glowing Compassion, Hearty Wisdom, Acclaimed Competence and Countless Opportunities.

Figure 1 shows the Thomasian Success Progress that clearly described what the Thomasian Board Topnotchers have gone through as they strive to achieve academic success.

The Thomasian Board Topnotchers initially began with the emerging theme Dreamed Beyond Our Seeing that captured their insights of triumph as most of the Thomasian Board Topnotchers envision themselves achieve a top rank in the PNLE.

For them, the ardor to success was coupled with their dream to go afar their own limits and abilities. Thomasian topnotchers also believe that their success in the PNLE started from their very first day in college as

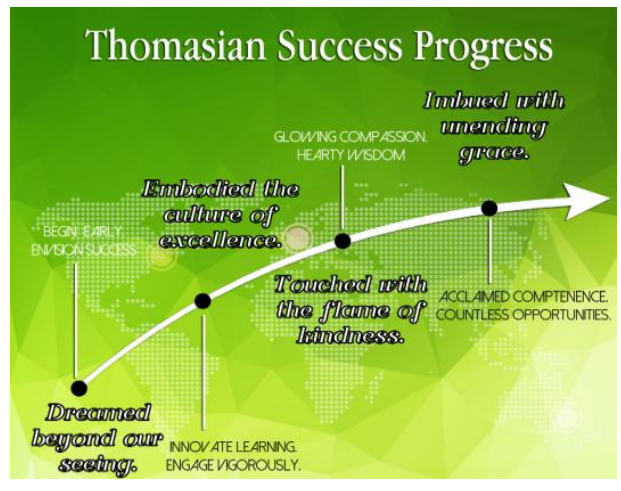

Fig1. Thomasian Success Progress 


\section{ThOMASIAN SUCCESS PROGRESS}

Student nurses. Begin Early and Envision Success are the two subthemes identified based from the Thomasian PNLE topnotchers experiences and have highlighted what the topnotchers have done to condition themselves to succeed not on a daily basis but for the whole four years of completing the nursing program.

Embodied the Culture of Excellence as the second emerging theme reflected what Thomasian Board Topnotchers have to imbibe the culture of excellence in learning. As for them, they do not just passively accept the information but actively search for why's and how's. The feeling of not knowing a lot of concepts, made them learn new things. In the process, it made them feel more humbled that they need to learn more each day. Innovate learning involves use of creative strategies they individually employ to assist themselves in the efficient learning of the nursing concepts they need to know at hand. Engaging vigorously highlighted their enthusiastic efforts to achieve success in their profession and the Philippine Nurses Licensure Exam. For most of them, their determination to be on top liven up their spirits to commit with competence. This energy does not change since first year and has been maintained until they prepare for the board exam. This include their active participation to learning, personal efforts to increase nursing knowledge such as regular attendance to lecture, RLE, enrichment and review classes.

The third emerging theme Touched with the flame of kindness described the Thomasian Board Topnotchers experiences of being nurtured by their academic environment as they progress toward personal and professional growth. For most of them, the institution have shaped them at their best, and were given the trust to excel. The Thomasian Board Topnotchers claimed that they attribute their success from the quality of education that they have obtained out of the burning love and benevolence of their professors, lecturers and nurse educators. In the subtheme Glowing Compassion, they affirmed their experience of caring from the institution who have been very mindful of their mental, emotional, social and spiritual needs as they were prepared to become better professionals. They shared the caring experiences they had from the college of nursing and the faculty, and how these experiences of caring turn them to become successful individuals. Hearty Wisdom as a subtheme mirrors their realization that the USTCON have taught them to value what they have learned so they can share it to others, love what they do so patients may experience love, and let nursing live in their hearts so they can never get tired of being a nurse to each and every one they encounter.

Lastly. The fourth emerging theme Imbued with Unending Grace highlighted their statements of triumph and poise after they have magnificently topped the Philippine Nurses Licensure Exam. It marks the Thomasian Board Topnotchers experience of victory and how it positively affected their professional life at present. Notably, they have experience a boosted morale, higher enthusiasm to excel more in their workplaces and gained a deeper motivation to care for their patients as reflected in its subthemes Acclaimed Competence and Countless Opportunities. Significantly, all of them identified several benefits after their PNLE success such as being top priority to hospital trainings in national and international healthcare field, abundant work opportunities, and scholarship grants to school of Medicine in the Philippines. These have left them endless chances to realize and create their sense of purpose.

Additionally, the findings of the study have revealed that the four emerging themes identified are the success targets that they had to individually achieve to be able to claim a top rank in the PNLE. Their success journey began as they started their nursing program and ended on the day of the exam. As each of the success targets have been successfully achieved, this also corresponds to the fulfilment of the Thomasian Nurse Core Values as shown in Figure 2. The Thomasian Board Topnotchers had gained an invaluable insight after four years of academic training and professional building as they concretize the Thomasian Core Values of Leadership, Innovation, Excellence, Compassion and Respect.

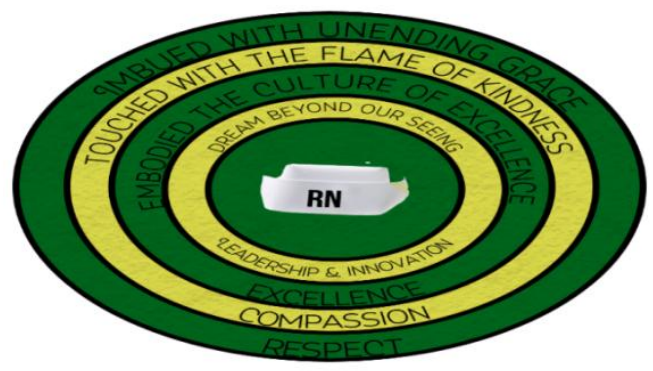

Fig2. Thomasian Board Topnotcher Success Target 
Dreamed Beyond Our Seeing as an emerging theme is a validation of the Thomasian Core Value of Leadership imparted by the institution from the beginning of their nursing education. Leadership involves empowering thomasian nurses to become productive, efficient and be of selfless service to others. The Thomasian Topnotchers affirmed that they have been leading their life to success from the time they have commit to devote themselves into the profession of human service until the time they have been licensed to care for human life. The thomasian PNLE topnotchers have proven their exceptionality as they greatly dominated the licensure examination.

Innovate Learning as a subtheme is an affirmation of the Thomasian Core Value of Innovation. Thomasian nurses must not limit their creativeness, utilize critical thinking in planning and decisions-making, formulate new ideas and actively participate in knowledge building. They must always allow themselves to be refined by the knowledge they gained over time. The topnotchers learning strategies and attitude toward academic rigor surfaced in this emerging theme. Their narrative accounts reflect how they process information, synthesize concepts, and apply nursing knowledge.

Rooted from the Thomasian Nurse Core Values of Excellence, thomasian nurses are expected to be in continuous commitment to achieve higher levels of quality. For most of the topnotchers, they believe that their success during the licensure examination was a product of their endless determination to learn and the four years of hardwork as nursing students. They have been used to engage actively into several learning opportunities since first year which optimizes their retention and understanding of basic nursing concepts.

Glowing Compassion as a subtheme strengthens the Thomasian Core Value of Compassion and Respect as thomasian nurses were expected to become sensitive to the needs of others. In this subtheme, the Thomasian Board Topnotchers affirmed their experience of caring from the institution who have been very mindful of their mental, emotional, social and spiritual needs as they were prepared to become better professionals. They shared the caring experiences they had from the college of nursing and the faculty, and how these experiences of caring turn them to become successful individuals.

\section{VISUALIZE SUCCESS}

Seeing what you want to happen for your future and believing that you can make it real was found to be effective for Thomasian PNLE topnotchers. Success demands being engulfed with optimism and willpower to concentrate on accomplishing what you want to attain. Rosaroso, Top 3 PNLE 2013, shared "I always had a mindset that I am going to top the board exams... Unfailingly, I woke up every morning believing that every minute I spend studying is a stepping stone towards my ultimate goal." Similarly, Tanquieng, Top 8, PNLE 2014 agreed by sharing "I have always wanted to be successful in whatever I do and I have always put that as one of my top priorities." Intrinsic motivation serves as a driving force in achieving one's goal in life and is critically linked to academic performance (Zajacove, Lynch, \& Espenshade, 2005; Valentine, Dubois \& Cooper, 2004; Chemers, Hu \& Garcia, 2001).

Success for student nurses may mean consistent academic achievement such as being in the deans' list, graduation, first time pass rate in the licensure exam and post-graduation employment. Success can also mean achieving more than minimum benchmarks - that is - achieving personal satisfaction and reaching beyond the benchmarks to achieve one's potential and then strive for more. For most of the thomasian topnotchers, success for them is a journey of going through a gradual process of refinement from college admission to employment. The idea that the journey was marked by "struggle" seemed to make the experience more significant to them. This challenging view requires the thomasian topnotchers to maintain their ongoing commitment to professional self-development. This approach is consistent with the characteristics of a profession that must be instilled upon entry into professional education and nurtured throughout all levels of education and beyond (in the workplace, professional associations, mentoring, and networking). Optimizing outcomes benefits individuals, the nursing profession, the health care system, patients, organizations, and society at large (Jeffreys, 2015).

\section{BEGIN EARLY}

Success is imminent once an individual has committed self to claim it. Setting clear goals as initial steps to envision success demands being engulfed with optimism and willpower to concentrate on accomplishing what you want to attain as confirmed by Rosaroso, Top 3, PNLE 2013 affirmed this finding as she wrote "When you claim very early on that you will be a topnotcher, everything just follows naturally." Students who are self-assured (Komarraju \& Nadler, 2013) and confident have greater academic performance and lead to successful completion (Zimmerman \& Kitsantas, 2005). Janas, Top 4 PNLE 2014 added "you should not only prepare for the boards during your review, preparing earlier is better." Also, Santos, Top 8, PNLE 2013 wrote "from the start of review classes, until the end, I 
had a goal setting, which is to top the board exams and give my best shot. Rosaroso, Top 3 PNLE 2013, added "I always had a mindset that I am going to top the board exams... Unfailingly, I woke up every morning believing that every minute I spend studying is a stepping stone towards my ultimate goal." These findings were significant to the study of Chowdhury and Shahabuddin (2007) who found that students who had higher levels of intrinsic and extrinsic motivation and increased self-beliefs of success attain the highest level of academic performance. Better academic performance results from consistent beliefs that one is capable of doing and highly motivated to complete tasks (Gore, 2006).

Additionally, being mindful of personal achievements and being focused on prioritizing success were proven to be helpful for the topnotchers. Cesa, Top 3 of 2014 PNLE, "Keep your eyes on the prize. You can only hit the bull's eye when you know what you are aiming for. You can never finish anything when there is no visible endpoint. Because when you know where you want to be in the end, you'll get there, no matter how difficult or how long the journey may be." Students with strong, resilient, and realistically appraised self-confidence view new tasks as challenges, meet tasks willingly, exert much energy and commitment, prepare diligently, utilize available resources, recognize limitations, are highly motivated, and aim to optimize outcomes and reach for their dreams (Jeffreys, 2015).

\section{Do MORE THAN WHAT YOU CAN}

Contemporary practice environments are complex and require students to possess high-level thinking capabilities to ensure patient safety and quality of care (Ironside, 2005). Nursing students who have high levels of self-efficacy tend to expect more from themselves and set high standards in achieving their goals. This finding was affirmed by Santos, Top 8, PNLE 2013, when she wrote "Set your goal higher and try to exceed your own limitations. From the start of the classes until the end, I had a goal setting, which is to top the board exams and to give my best shot." Tanquieng, Top 8, PNLE 2014, added further "I have always tried to push myself to study more and more even though I felt that I have already studied enough." Santos and Tanquieng believed that challenging your inner potential must be initiated and constantly maintained as you try to progress gradually in achieving your goals. Conscientious individuals are likely to be high achievers as they have a strong work ethic and are more likely to use deliberative, focused learning strategies (Komarraju, Karau, Schmeck \& Avdic, 2011).

\section{TRANSFORM YOUR OWN LEARNING}

In this study, it was found that the Thomasian Nurse Topnotchers developed study techniques to facilitate deeper understanding of nursing concepts. This finding is supported by study conducted by Komarraju, Karau, Schmeck and Avdic (2011) who stated that students who are organized, disciplined, determined, and intellectually curious are more likely to use a variety of learning styles such as synthesis analysis, elaborative processing, methodical study and fact retention in maximizing their learning. Methodical Study and Fact retention are agentic/shallow processing (with the performance goal of doing well on a test) while Synthesis analysis and Elaborative processing are reflective/deep processing (with the mastery goal of deep understanding and long-term retention). It was worthy to note that out of the four learning styles mentioned in their study, Thomasian topnotchers employ reflective styles, such as synthesis-analysis and elaborative processing as both are conducive to greater understanding and knowledge (Schmeck, 1999).

As shared by Tanquieng, Top 8, PNLE 2014, "I have allotted extra time every day to study and reflect on to the things I have learned. I have always studied not for the sake of grades but for understanding. I always try to understand my lessons instead of just memorizing them, even though this would take more time to do." Seno, Top 8, PNLE 2012 shared the same strategies as she wrote "I took each learning opportunity as it came and refused to move forward or leave the topic until I was able to comprehend it. By this, I did not have to rely on short term memory because I merely memorized; the underlying concepts came back to me in the boards because I understood it from way back."

Synthesis-analysis as defined in their study refers to processing information, forming categories, and organizing them into hierarchies. It was found that nursing students of the USTCON have developed an organized strategy in learning that helped them improved their academic performance. They have utilized memory strategies as defined by Magno (2010) as rewriting and taking notes, making a summary of readings, use of note cards and reciting notes while studying for an exam. The results of the study complement the established findings relating to organizing as one of the factors that may improve academic performance (Bostrom \& Hallin, 2012; Komarraju, Karau \& Schmeck, 2009; Bostrom \& Lassen, 2006). Highlighting significant information facilitated easier understanding and recall of their topics. Additionally, instructors who employ techniques that nurture synthesis-analysis and elaborative processing may be more likely to generate greater student interest and achievement (Komarraju, Karau, Schmeck \& 
Avdic, 2011). In this study, the Thomasian topnotchers shared that their professors/instructors explained a concept or theory by giving personal life examples, refers concepts to relevant current events, and illustrated the knowledge using hierarchical concepts, or organizes information around meaningful themes that assisted them to process information more thoughtfully.

Elaborative processing refers to connecting and applying new ideas to existing knowledge and to the learner's personal experiences. According to Komarraju et al (2011), those who are likely to be very thorough, relate what they are learning to previous knowledge and to their own lives, and to study in a systematic way excel on exams. Thomasian Board Topnotchers shared a variety of activities such as repetitive reading of previous notes, creating their own diagrams and flowcharts to facilitate clear understanding, prepared memory note cards and visual aids, answered sample tests and review rationale at their preferred pace. Concept mapping diagrams the critical thinking strategy involved in using the nursing process. Concept maps show the flow of thought processes and require analyzing, synthesizing, and evaluating information to determine an action or nursing intervention (Abel \& Freeze, 2006).

Achieving towards meaningful learning has led the thomasian nurses to success. Cesa, Top 3, PNLE 2014, highlighted "I was able to land a spot in the list of PNLE topnotchers because I have developed a mental skill that I am continuously trained of and diligently applied in the four years of my stay in the College of Nursing, giving me good comprehension of important concepts taught to us.

\section{Conclusion}

A retrospective qualitative inquiry was conducted to highlight the success experience of thirteen Thomasian Board Topnotchers for the past three years, 2012-2014.The study utilized a researcher made, semi-structured survey questionnaire that allowed the participants to share how they successfully achieved a top rank in the nurse licensure exam. The survey questionnaire was individually sent to their e-mail address after they voluntarily agreed to participate in the study. Interpretation and analysis of data was done following Collaizzi. Four emerging themes and eight subthemes captured their experiences as they prepared to successfully top the Philippine Nurses Licensure Exam for the past three years. These are the following namely: Dreamed Beyond Our Seeing with two subthemes Envision Success and Begin Early, Embodied the Culture of Excellence and its subthemes Innovate Learning and Engage Vigorously, Touched with the Flame of Kindness and the two subthemes Glowing Compassion and Hearty Wisdom and lastly, Imbued with Unending Grace with the two subthemes Acclaimed Competence and Countless Opportunities. The Thomasian Board Topnotchers have revealed a success target that clearly guided them to maintain academic rigor and reach academic victory. According to them, each target must be successfully attained to be able to transcend the licensure exam for nurses.

\section{RECOMMENDATION}

In this study, it was significant to note that the thirteen Thomasian Board Topnotchers have identified success targets that led them to attain a top rank in PNLE. Four basic hierarchical targets were shared by the Thomasian Board Topnotchers. The topnotchers began their targets with Visualizing Success, Begin Early, Do more than what you can and lastly, Transforming your own learning as seen in Figure 3.

The study revealed that their success in PNLE began when they envisioned themselves to succeed and started earlier when they were in their first year in nursing education. They have shared that their success in PNLE was a result of their four years of consistent academic hard work and not only because of the enrichment/review classes offered by the college to prepare them for the licensure exam. They even highlighted the importance of developing an organized learning strategy and transforming their own learning to deep approach. Goal setting, intrinsic motivation, optimism, self-discipline, structured learning and nurturing environment were among the many factors that the Thomasian Board Topnotchers mentioned that guided them toward success.

Thus, this study recommends to the future PNLE takers and schools of nursing in the country the use of PNLE Topnotcher Success Targets as their systematic approach to outshine the licensure exam for nurses. Aspiring PNLE Topnotchers must visualize their success, and that is to see themselves to be at the top rank in PNLE, begin early from their first year in Nursing Education, do more than what they can and unleash their inner potentials and lastly, aim for meaningful learning, 


\section{Nursing Students}

The study suggests that nursing students must strive to uphold constant academic rigor during the four years of their nursing education. Nursing students who aspire to become PNLE topnotchers must prepare early and begin their success journey at their first year in nursing. Intrinsic motivation must not cease to exist in their four years of knowledge building so that their drive to excel will continue until the scheduled day of the licensure exam. SelfDiscipline and optimism must keep them on their track to success. As the Philippine Nurses Licensure Exam measures the minimum competency level of graduate nurses by testing their ability to answer correctly questions lifted from theories and case scenarios encountered in the health care setting, thomasian student nurses must create their own strategies to innovate their learning and understand each nursing concept at a deeper level.

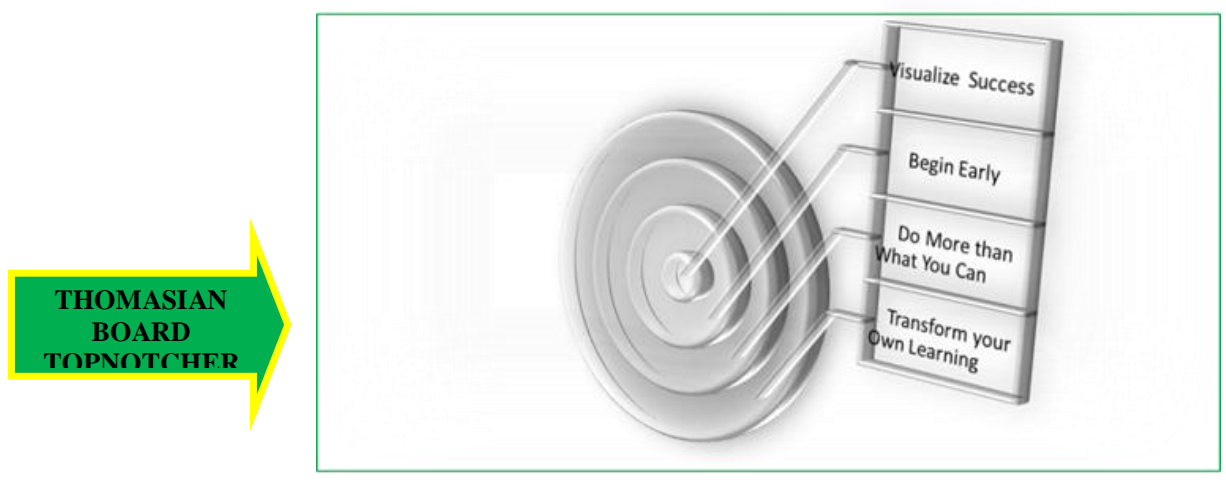

Figure 3: PNLE Topnotcher Success Targets

\section{Nursing Administration}

The study suggests that the administration must start to encourage their students to top the PNLE earlier at their first year of nursing education. Plans and programs to motivate them to succeed must not only exist before they graduate. Career Orientation and Opportunity Awareness must be started as they enter the nursing program. Student Development activities must be present for every level and must be done on an annual basis. The study also recommends the involvement of the Board Topnotchers during the Freshmen Orientation as Motivational speakers to share their experiences and heightened the students desire to excel. A Circle of Nurse Achievers must be created involving Board Topnotchers as a group to facilitate open communication with student nurses and graduate nurse achievers. This will aid the administration nurture patriotism among their students and graduates, update nursing practice, build linkages and establish work opportunities for future graduates as most of them were working in several areas of the nursing profession here and overseas. Moreover, the administration must continue to appreciate the untiring efforts of their faculty members who have exceeded beyond their role as educators and served as a nurturer of knowledge and model of excellence and compassion. The success of the Board Topnotchers in the PNLE may not be possible without them.

\section{Nursing Education}

This study suggests that nurse educators and professors must continue their optimistic attitude in teaching to increase the nursing students' commitment and passion to engage in life-long learning. Nurse Educators must structure learning activities of students and facilitate deep approach. Innovative strategies must be provided to increase retention, understanding and application of nursing concepts. Nurse educators can take a proactive approach and assist students in realistic self-appraisal of environmental and academic factors influencing success. Routinely appraising student progress to create a composite of potential variables supporting success is highly suggested. Student success is dependent upon the learning experiences in classroom, clinical, and laboratory learning environments. Faculty need to utilize strategies that integrate engaging learning activities into the curriculum, thereby improving Philippine Nursing Licensure Examination (PNLE) first-time pass rates.

\section{Nursing Research}

This study suggests that a quantitative study will be done to solidify and validate the identified factors that really helped the Thomasian Board Topnotchers achieve their success. Also, other related factors such as personality types, 
gender and academic consistency must be examined using the same method of inquiry. Also, a longitudinal study is suggested to be able to track the academic performances of nursing students from first year to fourth year and correlate the findings with self-efficacy, motivation and learning environment.

\section{Commission on Higher Education}

The findings of this study would help in the formulation of policy by the Professional Regulation Commission to regarding predictive factors of success in the board examination. Examining the relationships among admissions criteria, performance in nursing courses and PNLE results assists programs in strengthening admissions and progression policies so that students selected to begin nursing courses have the best possibility of completing the typically rigorous curriculum.

\section{REFERENCES}

[1] Abel, W., \& Freeze, M. (2006). Evaluation of concept mapping in an associate degree nursing program. Journal of Nursing Education, 45(9). 356-364.

[2] Bristol, T., (2012) The National Council Licensure Examination across the curriculum: Low-tech learning strategies for student success. Teaching and Learning in Nursing, 7 80-84.

[3] Bostrom, L. and Hallin, K. (2012) Learning \& Style Differences between nursing and Teaching Students in Sweden: A Comparative Study. International Journal of Higher Education, 2 (1), 22-34.

[4] Boström, L., and Lassen, L. (2006) "Unraveling Learning, Learning Styles, Learning Strategies and Meta-Cognition." Education + Training 48.2/3: 178-89.

[5] Chemers, M. M., Hu, L.-T., and Garcia, B. F. (2001). Academic self-efficacy and first-year college student performance and adjustment. Journal of Educational Psychology 93(1): 55-64.

[6] Chowdhury, M., \& Shahabuddin, A. (2007). Self-efficacy, motivation and their relationship to academic performance of Bangladesh college students. College Quarterly, 10(1), 1-9.

[7] Divinagracia, C., Palaganas, E., Rosales, A. (2012) Nurse Licensure Examination Performance of Graduates of Philippine Colleges of Nursing in the Philippines: Policy Implications

[8] Gore, P. A. (2006). Academic self-efficacy as a predictor of college outcomes: Two incremental validity studies. Journal of Career Assessment, 14,92 - 115.

[9] Guba, E. G., \& Lincoln, Y. S. (1994). Competing paradigms in qualitative research. In N. K. Denzin \& Y. S. Lincoln (Eds.), Handbook of qualitative research 105-117. London: Sage.

[10] Haghverdi, H.R., Biria, R.,Karimi, L. (2010). The effect of note-taking strategy instruction on the students' academic achievement. Journal of Asia TEFL, 7(2), 123-151.

[11] Ironside, P., (2005). Teaching Thinking and Reaching the Limits of Memorization: Enacting New Pedagogies. Journal of Nursing Education 44(10) 441-449.

[12] Jeffreys, M. (2007).Tracking students through program entry, progression, graduation, and licensure: Assessing undergraduate nursing student retention and success. Nurse Education Today 27(5), 406-419.

[13] Komarraju, M., \& Nadler, D. (2012). Self-Efficacy and academic achievement: Why do implicit beliefs, goals and effort regulation matter? Learning and Individual Differences. 67-72.

[14] Komarraju, M., Karau, S., Schmeck R., \& Avdic, A., (2011). The Big Five personality traits, learning styles, and academic achievement. Personality and Individual Differences, 51 472-477.

[15] Komarraju, M., Karau, S. J., \& Schmeck, R. R. (2009). Role of the Big Five personality traits in predicting college students' academic motivation and achievement. Learning and Individual Differences, 19, 47-52.

[16] McLaughlin, K., Moutray, M.,Muldoon, O.T., 2008. The role of personality and self-efficacy in the selection and retention of successful nursing students: a longitudinal study. J. Adv. Nurs. 61 (2), 211-221. http://dx.doi.org/10.1111/j.13652648.2007.04492.x.

[17] Magno, C. (2010) Assessing academic self-regulated learning among Filipino college students. The factor structure and item fit. The International Journal of Educational and Psychological Assessment, 5(1), 61-78.

[18] Ordonez, G., \& Ordonez, V. (2009). Accreditation in the Philippines: a case study. Higher Education in Asia/Pacific Quality and the Public Good. Edited by Terance W. Bigalke and Deane E. Neubauer. Series: International and Development Education. Palgrave Macmillan.

[19] Rosales, A., Arugay, Y., Divinagracia, C. Palaganas, E. (2014) Analytical Study of the Nurses Licensure Examination Performance of Graduates of Philippine Colleges of Nursing. Philippine Journal of Nursing 84(1) 4-23.

[20] Schmeck, R. R. (1999). Thoughtful learners: Students who engage in deep and elaborative information processing. In R. J. Riding \& S. G. Rayner (Eds.), International Perspectives on Individual Differences. Stamford: Ablex Publishing.

[21] Valentine, J.C., DuBois, D.L., \& Cooper, H.2004. The relations between self-beliefs and academic achievement: A meta-analytic review. Educational Psychologist 39: 111-133.

[22] Zajacova, A., Lynch, S. M., \& Espenchade, T.J. (2005). Self-Efficacy, Stress, and Academic Success in College. Research in Higher Education, 46(6). doi: 10.1007/s11162-004-4139-z

[23] Zimmerman, B. J., \& Kitsantas, A. (2005). Homework practices and academic achievement: The mediating role of selfefficacy and perceived responsibility beliefs. Contemporary Educational Psychology, 30, 397-417. 